\title{
CORRECTION
}

\section{Correction to: The bony labyrinth of Qafzeh 25 Homo sapiens from Israel}

\author{
Dany Coutinho-Nogueira ${ }^{1,2} \cdot$ Hélène Coqueugniot ${ }^{1,2} \cdot$ Frédéric Santos $^{1} \cdot$ Anne-marie Tillier $^{1}$
}

Published online: 27 December 2021

(c) The Author(s), under exclusive licence to Springer-Verlag GmbH Germany, part of Springer Nature 2021

Correction to: Archaeological and Anthropological Sciences (2021) 13: 151

https://doi.org/10.1007/s12520-021-01377-2

The wrong Supplementary file was originally published with this article; it has now been replaced with the correct file.

The original article has been corrected.

Publisher's note Springer Nature remains neutral with regard to jurisdictional claims in published maps and institutional affiliations.

The original article can be found online at https://doi.org/10.1007/ s12520-021-01377-2.

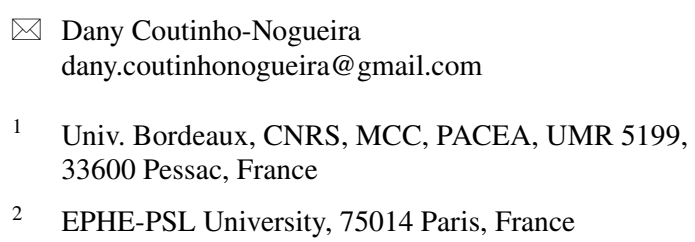

2 EPHE-PSL University, 75014 Paris, France 